\title{
Clinico-demographic pattern of childhood onset vitiligo at a tertiary care centre in Chhattisgarh
}

\author{
Dilip Kumar Sa ${ }^{1}$, Rakesh Kumar Patel ${ }^{2, *}$ Akhilesh Behra ${ }^{3}$, Kamalini Meher ${ }^{4}$ \\ ${ }^{\mathbf{1}}$ Associate Professor ${ }^{\mathbf{2 , 3}}$ Assistant Professor, ${ }^{\mathbf{4}}$ Senior Resident, Dept. of Dermatology, LSLAM Government Medical College, \\ Raigarh, Chhattisgarh, India
}

*Corresponding Author:

Email: rakesh99331@gmail.com

\begin{abstract}
Introduction: Vitiligo is an acquired depigmenting disorder having a major impact on quality of life. Childhood onset vitiligo differs from adult onset vitiligo in demographic and clinical characteristics.

Aim: To study the clinico-demographic pattern of childhood onset vitiligo.

Materials and Methods: Consecutive patients of vitiligo attending Dermatology OPD from April, 2017 to March, 2018 with history of onset of disease before the age of 12 years were evaluated. A detailed history, examination findings, laboratory parameters and VIDA and VASI score were recorded and statistical analysis was done.

Results: Of the 120 patients recruited for the study, 48 were male and 72 were female. The mean age of onset of disease was 8.18 years. The most common age group affected was 5 to 10 years $(50 \%)$. The mean duration of disease was 1.81 years. The most common site affected was head \& neck $(56.66 \%)$, followed by lower limb $(26.66 \%)$, trunk $(23.33 \%)$, upper limb (15\%) and mucosa (15\%). The most common site of onset was eyelids $(37.5 \%)$. The most common pattern of vitiligo was segmental vitiligo $(30 \%)$. Leukotrichia was found in $15 \%$ and Koebner phenomenon in $19.16 \%$. Autoimmune association was found in $5 \%$ and association with other cutaneous conditions in $7.5 \%$. VIDA score was +4 in $35 \%,+3$ in $16.66 \%,+2$ in $10 \%,+1$ in $26.66 \%, 0$ in $6.67 \%$ and -1 in $5 \%$.
\end{abstract}

Conclusion: The most common site of onset was eyelids. The most common pattern was segmental vitiligo. Autoimmune association and association with other skin disorders were less in our study.

Keywords: Childhood, Vitiligo, Leukotrichia, Koebner, Autoimmune, VIDA.

\section{Introduction}

Vitiligo is an acquired pigmentary disorder of skin and mucous membrane characterized by circumscribed depigmented macules due to localized loss of melanocytes. It affects about $1 \%$ of world's population. ${ }^{1}$ It is a cosmetically disturbing condition with a major impact on quality of life because of the associated social stigma. Childhood vitiligo deserves special attention as in $25 \%$ cases it starts before the age of 10 years and in $50 \%$ cases before the age of 20 years. ${ }^{2}$ Childhood onset vitiligo (COV) may be quoted as disease occurring with onset before the age of 12 years. ${ }^{3}$ Childhood vitiligo has been broadly categorized as segmental and non-segmental. Segmental vitiligo implies lesions in dermatomal or quasi-dermatomal pattern without crossing the midline. Non-segmental vitiligo is again classified into generalized (vitiligo vulgaris and universalis) and localized (focal, acral, acrofacial, mucosal). ${ }^{4}$ Koebner phenomenon is more common in childhood vitiligo because of higher mobility of children. ${ }^{5} \mathrm{COV}$ may be associated with other autoimmune disorders like autoimmune thyroiditis, alopecia areata, type 1 diabetes mellitus, pernicious anemia, Addison's disease and other skin disorders like atopic dermatitis, halo nevi and psoriasis. COV mimics nevoid conditions like nevus depigmentosus \& nevus anemicus, hereditary conditions like piebaldism, Waardenburg syndrome and many acquired skin disorders like pityriasis alba, lichen striatus, pityriasis versicolor, leprosy, postinflammatory hypopigmentation etc. ${ }^{5}$

In the present study, we aimed to evaluate the clinico-demographic pattern of $\mathrm{COV}$ and its association with other cutaneous \& autoimmune disorders.

\section{Materials and Methods}

The study was performed in the Department of Dermatology, LSLAM Govt. Medical College, Raigarh, Chhattisgarh, India between April, 2017 to March, 2018. Consecutive patients of vitiligo having a history of onset of disease before the age of 12 years and giving consent for the study were recruited for the study. The diagnosis of vitiligo was made based upon clinical features and Wood's lamp examination. A complete history was taken including age, sex, duration of disease, age of onset, site of onset, course of disease, family history, history of trauma, history of associated skin or systemic conditions. A thorough clinical examination was done to evaluate the site, pattern, presence of luekotrichia, Koebner phenomenon and association with other skin conditions like atopic dermatitis, alopecia areata, halo nevus, psoriasis. Vitiligo disease activity (VIDA) score was evaluated for all patients. VIDA is a six point scale for assessing vitiligo activity and scoring is done based on individual's own opinion of present disease activity over time. VIDA score +4 means disease active in past 6 weeks, +3 means diseases active in past 3 months, +2 when disease is active in past 6 months, +1 when 
disease active in past 1 year, 0 means disease stable for at least one year and -1 when disease is stable for at least 1 year and showing spontaneous repigmentation. ${ }^{6}$ Vitiligo area severity index (VASI) was determined by product of area of vitiligo in hand units and degree of depigmentation within each hand unit measured patch. ${ }^{7}$ Routine investigations like complete blood count, liver function test, renal function test, blood sugar, urine examination and thyroid function test were performed. Thyroid peroxidase antibody (TPO) test was sought in all cases with raised thyroid stimulating hormone (TSH) level. Statistical analysis was done using Microsoft Office Excel 2007.

\section{Results}

The salient observations of our study are summerized in Table 1

During the study period, 577 new cases of vitiligo attended our dermatology OPD. Among them 128 $(22.18 \%)$ patients had a history of disease onset before the age of 12 years but 8 patients were excluded from the study as they did not give consent. Of the 120 patients recruited for the study, 48 were male and 72 were female. 15 patients $(12.5 \%)$ belonged to age group 0 to 5 years, 60 patients $(50 \%)$ belonged to age group 5 plus to 10 years and rest 45 patients $(37.5 \%)$ were more than 10 years of age. The most common site of distribution of lesions was head and neck (56.66\%). The site of onset of lesion was head \& neck in 61 cases $(50.83 \%)$, trunk in 16 cases $(13.33 \%)$, upper limb in 10 cases $(8.33 \%)$, lower limb in 20 cases $(16.67 \%)$ and mucosa in 13 cases $(10.83 \%)$. Of the head \& neck region, eyelids were the most common site of onset. Segmental vitiligo Fig. 1 was the most common pattern followed by focal vitiligo Fig. 2, vitiligo vulgaris Fig. 3, mucosal vitiligo Fig. 4 and acrofacial vitiligo Fig. 5 in decreasing order. 19 cases $(15.83 \%)$ had a history of vitiligo in first degree relatives. Autoimmune thyroiditis and atopic dermatitis were the most common autoimmune and cutaneous associations respecetively. VIDA score was 0 or -1 in $11.67 \%$ cases (stable vitiligo) and between +1 to +4 in $88.33 \%$ cases (unstable vitiligo).

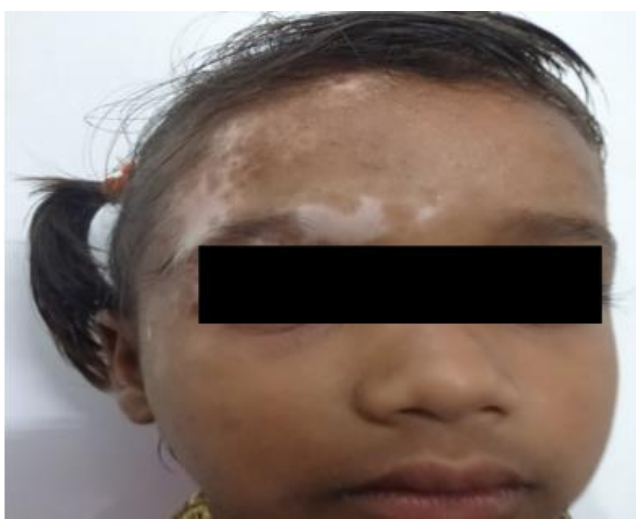

Fig. 1: Segmental vitiligo

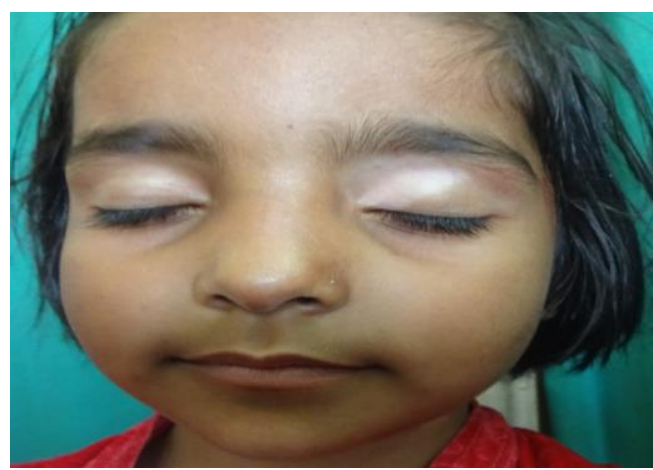

Fig. 2: Focal vitiligo

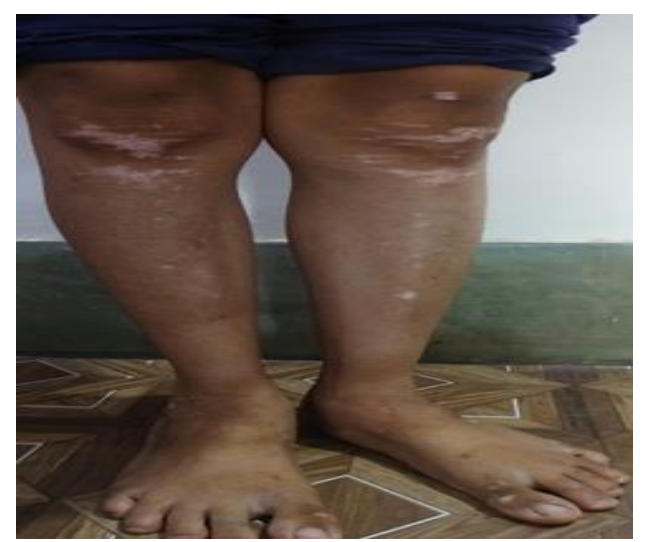

Fig. 3: Vitiligo vulgaris

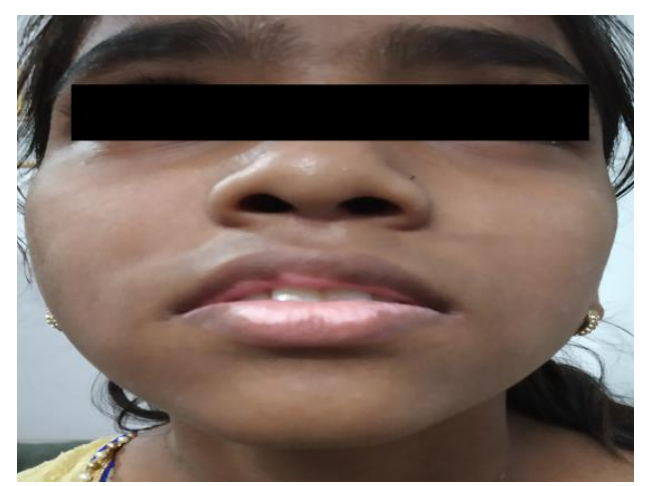

Fig. 4: Mucosal vitiligo

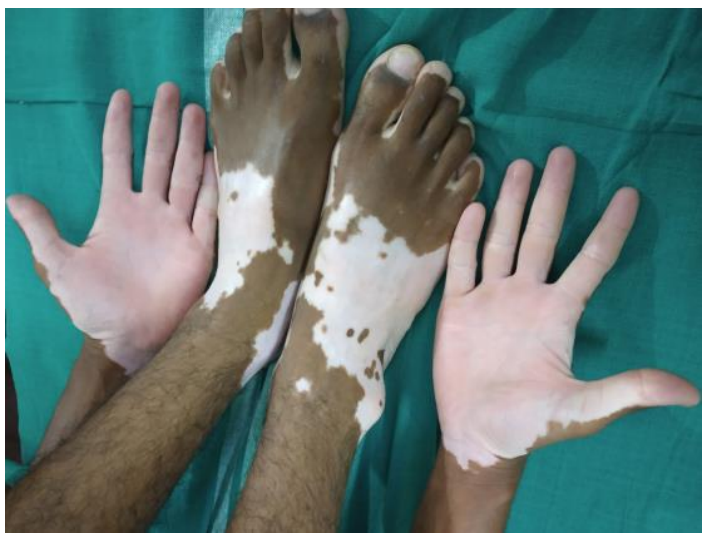

Fig. 5: Acro-facial vitiligo 
Table 1: Clinico-demographic pattern of childhood onset vitiligo (n=120)

\begin{tabular}{|c|c|}
\hline Variable & Results \\
\hline Most common age group & 5 to 10 years \\
\hline Mean age of onset of disease & 8.18 years \\
\hline Male to female ratio & $1: 1.5$ \\
\hline Mean duration of disease & 1.81 years(range 2 months to 6 years) \\
\hline Site of lesions & $\begin{array}{c}\text { Head \&neck }(56.66 \%) \\
\text { Lower limb }(26.66 \%) \\
\text { Trunk }(23.33 \%) \\
\text { Upper limb }(15 \%) \\
\text { Mucosa }(15 \%) \\
\end{array}$ \\
\hline Most common site of onset of disease & Eyelids $(37.5 \%)$ \\
\hline Pattern of Vitiligo & $\begin{array}{c}\text { Segmental vitiligo }(30 \%) \\
\text { Focal vitiligo }(28.33 \%) \\
\text { Vitiligo vulgaris }(26.66 \%) \\
\text { Mucosal vitiligo }(10.83 \%) \\
\text { Acrofacial vitiligo }(4.16 \%) \\
\end{array}$ \\
\hline Family history & $24.16 \%$ \\
\hline Leukotrichia & $15 \%$ \\
\hline Koebner phenomenon & $19.16 \%$ \\
\hline $\begin{array}{l}\text { Autoimmune association } \\
\text { 1. Autoimmune thyroiditis } \\
\text { 2. Alopecia areata }\end{array}$ & $\begin{array}{c}5 \% \\
3.33 \% \\
1.67 \%\end{array}$ \\
\hline $\begin{array}{l}\text { Association with other cutaneous disorders } \\
\text { 1. Atopic dermatitis } \\
\text { 2. Halo nevus }\end{array}$ & $\begin{array}{l}7.5 \% \\
5.83 \% \\
1.67 \%\end{array}$ \\
\hline Hypothyroidism & $22.5 \%$ \\
\hline VIDA Score & $\begin{array}{c}+4(35 \%) \\
+3(16.66 \%) \\
+2(10 \%) \\
+1(26.66 \%) \\
0(6.67 \%) \\
\quad-1(5 \%)\end{array}$ \\
\hline $\begin{array}{l}\text { Mean VASI Score } \\
\text { 1. } \quad \text { VASI Score }>10 \\
\text { 2. } \quad \text { VASI Score }<10\end{array}$ & $\begin{array}{c}4.55 \\
7.5 \% \\
92.5 \%\end{array}$ \\
\hline
\end{tabular}

VIDA - Vitiligo disease activity, VASI - Vitiligo area severity index

Table 2: Comparison of salient observations by different Indian studies including present study

\begin{tabular}{|l|c|c|c|c|c|c|}
\hline Parameter & $\begin{array}{c}\text { Raju et al. } \\
(\mathbf{2 0 1 6})^{\mathbf{9}}\end{array}$ & $\begin{array}{c}\text { Sheth et } \\
\text { al.(2015) }\end{array}$ & $\begin{array}{c}\text { Kayal et } \\
\text { al.(2015) }\end{array}$ & $\begin{array}{c}\text { Agrawal et. } \\
\text { al.(2013) }\end{array}$ & $\begin{array}{c}\text { Handa et } \\
\text { al.(2003) }^{\mathbf{8}}\end{array}$ & $\begin{array}{c}\text { Present } \\
\text { study(2018) }\end{array}$ \\
\hline No. of patients & 180 & 100 & 109 & 268 & 625 & 120 \\
\hline $\begin{array}{l}\text { Male to female } \\
\text { ratio }\end{array}$ & $1: 1.6$ & $1: 1.2$ & $1: 1.48$ & $1: 1.3$ & $1: 1.3$ & $1: 1.5$ \\
\hline $\begin{array}{l}\text { Most common age } \\
\text { group (years) }\end{array}$ & $7-12$ & NS & $8-12$ & NS & $9-12 \mathrm{yrs}$ & $5-10 \mathrm{yrs}$ \\
\hline $\begin{array}{l}\text { Mean age of onset } \\
\text { (years) }\end{array}$ & 6.8 & 8.9 & 7.85 & 6.9 & 6.2 & 8.18 \\
\hline Family history (\%) & 24.3 & 14 & 19.27 & 24.3 & 12.2 & 24.16 \\
\hline Most common site & NS & $\begin{array}{c}\text { Lower limb } \\
(62 \%)\end{array}$ & $\begin{array}{c}\text { Head \& neck } \\
(46.1 \%)\end{array}$ & $\begin{array}{c}\text { Head \& neck } \\
(36.9 \%)\end{array}$ & NS & $\begin{array}{c}\text { Head \& neck } \\
(56.66 \%)\end{array}$ \\
\hline $\begin{array}{l}\text { Most common site } \\
\text { of onset of disease }\end{array}$ & $\begin{array}{c}\text { Head \& } \\
\text { neck }\end{array}$ & NS & Eyelids & NS & NS & Eyelids \\
\hline $\begin{array}{l}\text { Most common } \\
\text { pattern }\end{array}$ & $\begin{array}{c}\text { Vitiligo } \\
\text { vulgaris } \\
(37.8 \%)\end{array}$ & $\begin{array}{c}\text { Vitiligo } \\
\text { vulgaris } \\
(46 \%)\end{array}$ & $\begin{array}{c}\text { Vitiligo } \\
\text { vulgaris } \\
(48.6 \%)\end{array}$ & $\begin{array}{c}\text { Acrofacial } \\
\text { vitiligo } \\
(38.1 \%)\end{array}$ & $\begin{array}{c}\text { Vitiligo } \\
\text { vulgaris } \\
(78.4 \%)\end{array}$ & $\begin{array}{c}\text { Segmental } \\
\text { Vitiligo } \\
(30 \%)\end{array}$ \\
\hline
\end{tabular}




\begin{tabular}{|l|c|c|c|c|c|c|}
\hline Parameter & $\begin{array}{c}\text { Raju et al. } \\
\text { (2016) }^{\mathbf{9}}\end{array}$ & $\begin{array}{c}\text { Sheth et } \\
\text { al.(2015) }^{\mathbf{1 0}}\end{array}$ & $\begin{array}{c}\text { Kayal et } \\
\text { al.(2015) }^{\mathbf{1 1}}\end{array}$ & $\begin{array}{c}\text { Agrawal et. } \\
\text { al.(2013) }^{\mathbf{1 2}}\end{array}$ & $\begin{array}{c}\text { Handa et } \\
\text { al.(2003) }^{\mathbf{8}}\end{array}$ & $\begin{array}{c}\text { Present } \\
\text { study(2018) }\end{array}$ \\
\hline Leukotrichia (\%) & 41.8 & 25 & 26.6 & 32.5 & 12.3 & 15 \\
\hline $\begin{array}{l}\text { Koebner's } \\
\text { phenomenon (\%) }\end{array}$ & 24.6 & 21 & 36.7 & 24.3 & 11.5 & 19.16 \\
\hline $\begin{array}{l}\text { Autoimmune } \\
\text { association (\%) }\end{array}$ & 2.2 & 17 & 20.2 & NS & 1.3 & 5 \\
\hline $\begin{array}{l}\text { Association with } \\
\text { Atopic dermatitis } \\
(\%)\end{array}$ & 3.3 & 13 & 22.02 & 9.3 & NS & 5.83 \\
\hline $\begin{array}{l}\text { Association with } \\
\text { Halo nevus (\%) }\end{array}$ & 5 & 3 & 0.92 & 0 & 4.4 & 1.67 \\
\hline $\begin{array}{l}\text { VIDA Score (\%) } \\
+1 \text { to +4 } \\
\text { 0 to -1 }\end{array}$ & 79.5 & 91 & 84.4 & NS & NS & 88.33 \\
\cline { 2 - 7 } & 20.5 & 9 & 15.6 & NS & NS & 11.67 \\
\hline
\end{tabular}

NS - Not stated, VIDA - Vitiligo disease activity

\section{Discussion}

The prevalence of COV among all cases of vitiligo was reported to be $23.3 \%$ in a north-Indian study. ${ }^{8}$ In our study the prevalence of COV was found to be $22.18 \%$ which is in concordance with the above study.

A comparative analysis of various Indian studies on childhood vitiligo including our study is depicted in Table 2 .

The mean age of onset of disease in our study was 8.18 years which is almost similar to observations by Sheth et al. and Kayal et al. but slightly higher than the results of Handa et al. and Raju et al. ${ }^{8,9-11}$ In our study, the most common age group affected was 5 to 10 years contrary to 7 to 12 years by Raju et al. and 8 to 12 years by Kayal et al. ${ }^{9,11}$ Most India studies on childhood vitiligo observed female preponderance similar to our observation (Male to female ratio 1:1.5). ${ }^{8-12}$ This may be due to the fact that Indian parents are more concern for girls compared to boys due to cosmetic disfigurement and social stigma associated with vitiligo.

The mean duration of disease in our observation was 1.81 years which is higher than observations by Sheth et al. and $\mathrm{Hu}$ et al. ${ }^{10,13}$

In our study, the most common site of onset of lesion was eyelids. Kayal et al. also reported similar observation. ${ }^{11}$ Raju et al. found head \& neck to be the initial site of onset of lesion. ${ }^{9}$ The most common site of $\mathrm{COV}$ in present study was head and neck followed by lower limb, trunk, upper limb and mucosa respectively. This observation is in concordance with Kayal et al, Agrawal et al. and Puri et al. but Sheth et al. reported lower limb to be the most common site of COV. ${ }^{10-12,14}$ We found mucosal vitiligo in $15 \%$ cases and this finding is higher than that by Kayal et al. and Puri et al. ${ }^{11,14}$

In the present study, the most common pattern of COV observed was segmental followed by focal vitiligo, vitiligo vulgaris, mucosal vitiligo and acrofacial vitiligo. This finding is not consistent with majority of studies which found vitiligo vulgaris to be the most common pattern. ${ }^{8,9-11,14}$ Agrawal et al. found acro-facial type as most common pattern. ${ }^{12}$ A Korean study found the prevalence of segmental vitiligo to be higher in children (17-29\%) as compared to that in adults $(5 \%) .{ }^{15} \mathrm{We}$ also found focal vitiligo in $28.33 \%$ cases which is higher than observations by majority of studies. ${ }^{8,9,11,12}$ We observed mucosal vitiligo in $10.83 \%$ cases which is consistent with observation by Raju et al. ${ }^{9}$ This Fig. is much less in many other studies. ${ }^{8,11,12,16}$ We did not find any case of lip-tip vitiligo and vitiligo universalis in our study.

Family history was positive in $24.16 \%$ patients of $\mathrm{COV}$ which is very similar to Raju et al. and Agrawal et al. but is slightly higher than findings by Handa et al, Sheth et al. and Kayal et al.$^{8-12}$ First degree relatives were affected in $15.83 \%$ cases and second degree relatives in $8.33 \%$. Raju et al. also reported that first degree relatives are affected more than second degree relatives but Sheth et al. found the reverse., 910 Leukotrichia was found in $15 \%$ of our study population which is relatively less than observations by many Indian studies. ${ }^{9-12}$ Pajvani et al. have noted earlier onset of vitiligo in children with positive family history and leukotrichia. ${ }^{17}$

Due to higher mobility and playful attitude of children, Koebner phenomenon is more common in childhood vitiligo. It also indicates the disease activity. ${ }^{5}$ We noted Koebner phenomenon in $19.16 \%$ cases. This figure is low compared to that by Kayal et al. and Jain et al. ${ }^{11,16}$

Lacovelli et al. studied altered thyroid parametes in childhood vitiligo and concluded that $16 \%$ patients had altered thyroid function parameters and hypothyroidism to be six times more common than hyperthyroidism. ${ }^{2}$ Hypothyroidism was noted in $22.5 \%$ cases which is comparable to Kayal et al. ${ }^{11}$ Association with other autoimmune diseases like alopecia areata, autoimmune thyroiditis, pernicious anemia, Addison's disease, type 1 diabetes mellitus was found in $1.3 \%$ to $20.25 \%$ cases in various studies. ${ }^{8-11} \mathrm{We}$ found autoimmune association in 5\% cases. Of the 5\% cases, 3.33\% had 
autoimmune thyroiditis and $1.67 \%$ had alopecia areata. Various studies found alopecia areata in $0.32 \%$ to $3.4 \%$ cases. $^{9-11,13}$ Pajvani et al. noted an earlier onset of disease in children having an associated autoimmune disorder. ${ }^{17}$ Association with other cutaneous conditions like atopic dermatitis, psoriasis, halo nevus have been reported in various studies. Atopic dermatitis was found in $5.83 \%$ cases which is in agreement with Raju et al. and Jain et al. ${ }^{9,16}$ However, Kayal et al. noted this in a higher proportion of patients $(22.02 \%){ }^{11}$ Halo nevus was found in $1.67 \%$ of our cases. Various studies observed this in $0.92 \%$ to $8.57 \%$ cases..$^{8,9-11,16}$ We did not notice any association with Pernicious anemia, Addison's disease, type 1 diabetes mellitus and psoriasis.

VIDA score was +4 in $35 \%$ patients followed by +1 score in $26.66 \%,+3$ in $16.66 \%,+2$ in $10 \%$ cases. Thus, in $88.33 \%$ cases disease was progressive (VIDA +1 to +4$)$. Raju et al, Sheth et al. and Kayal et al. also had similar observation. ${ }^{9-11}$ The most common VIDA score was +4 in studies by Sheth et al and Kayal et. al. ${ }^{10,11}$ This is due to the fact that that patients seek treatment when the disease is progressive in recent period. Stable disease was seen in $11.67 \%$ cases which is in concordance with Sheth et al. and Kayal et al. ${ }^{10,11}$ History of spontaneous resolution was found $5 \%$ of our patients.

VASI > 10 was noted in $7.5 \%$ patients which is in agreement with Kayal et al. ${ }^{11}$ Handa et al. also observed that majority of children with vitiligo had $<20 \%$ body surface area involvement. ${ }^{8}$

\section{Conclusion}

We noted female preponderance because of higher cosmetic concerns among parents for girls. The most common age group affected was 5 to 10 years. Mean age of onset was slightly higher in our study compared to other studies. Most common site of onset of disease was eyelids. Segmental vitiligo was the most common pattern in our study unlike majority of studies. We noted vitiligo vulgaris in a lesser proportion of patients. Association with autoimmune disorders and other cutaneous disorders was also less in our study. The disease was progressive in $88.33 \%$ and VASI was less than 10 in $92.5 \%$ cases.

\section{References}

1. Anstey AV. Disorders of Skin Colour. In: Burns T, Breathnach S, Cox N, Griffiths C (Eds). Rook's Textbook of Dermatology, $8^{\text {th }}$ edn. Wiley-Blackwell Publishing Ltd. 2010. pp.58.46-9.

2. Lacovelli P, Sinagra JL, Vidolin AP, Maenda S, Capitanio B, et al. Relevance of thyroiditis and of other autoimmune diseases in children with vitiligo. Dermatology. 2005;210:26-30.
3. Dhar S, Banerjee R, Malakar R. Vitiligo in Children. In: Lahiri K, Chatterjee M, Sarkar R (Eds). Pigmentary Disorders: A Comprehensive Compendium, $1^{\text {st }}$ edn. Jaypee Brothers Medical Publishers (P) Ltd. 2014. pp.181-5.

4. Mazereeuw-Hautier J, Harper J. Vitiligo. In: Harper J, Oranje A, Prose N (Eds). Textbook of Pediatric Dermatology, $2^{\text {nd }}$ edn. Oxford: Blackwell Publishing Ltd. 2006. pp.1041-56.

5. Palit A, Inamadar AC. Childhood vitiligo. Indian J Dermatol Venereol Leprol. 2012;78;30-41.

6. Gupta V, Ramam M. Measuring Disease Severity in Vitiligo. In: Lahiri K, Chatterjee M, Sarkar R (Eds). Pigmentary Disorders: A Comprehensive Compendium, $1^{\text {st }}$ edn. Jaypee Brothers Medical Publishers (P) Ltd. 2014. pp.141-56.

7. Bhor U, Pande S. Scoring system in dermatology. Indian J Dermatol Venereol Leprol. 2006;72:315-21.

8. Handa S, Dogra S. Epidemiology of childhood vitiligo: A study of 625 patients from north India. Pediatr Dermatol. 2003;20:207-10.

9. Raju BP, Nagaraju U. Profile of childhood vitiligo with associated ocular abnormalities in South India. Indian J Pediatr Dermatol. 2016;17:179-85.

10. Sheth PK, Sacchidanand S, Asha GS. Clinicoepidemiological profile of childhood vitiligo. Indian $J$ Pediatr Dermatol. 2015;16:23-8.

11. Kayal A, Gupta LK, Khare AK, Mehta S, Mittal A, Kuldeep CM. Pattern of childhood onset vitiligo at a tertiary care centre in South-West Rajasthan. Indian J Dermatol. 2015;60:520.

12. Agrawal S, Gupta S, Ojha A, Sinha R. Childhood vitiligo: Clinicoepidemiologic profile of 268 children from the Kumaun region of Uttarakhand, India. Pediatr. 2013;30:348-53.

13. Hu Z, Liu JB, Ma SS, Yang S, Zhang XJ. Profile of childhood vitiligo in China: An analysis of 541 patients. Pediatr Dermatol. 2006;23:114-6.

14. Puri N. A clinico-epidemiological study on childhood vitiligo. Indian J Paediatr Dematol. 2016;17:101-3.

15. Chao S, Kang HC, Hahm JH. Characteristics of vitiligo in Korean children. Pediatr Dermatol. 2000;17:189-93.

16. Jain M, Jain SK, Kumar R, Mehta P, Banjara N, Kalwaniya S. Clinical profile of childhood vitiligo patients in Hadoti region in Rajasthan. Indian J Paediatr Dermatol. 2014;15:20-3.

17. Pajvani U, Ahmad N, Wiley A, Levy RM, Kundu R, Mancini AJ, et al. The relationship between family medical history and childhood vitiligo. J Am Acad Dermatol. 2006;55:238-44.

How to cite this article: Sa DK, Patel RK, Behra A, Meher K. Clinico-demographic pattern of childhood onset vitiligo at a tertiary care centre in Chhattisgarh. Ind J Clin Exp Dermatol. 2018;4(3):174-178. 